\title{
Application and Discussion of Multidimensional Interactive Model in Pathology Teaching of Nursing Specialty

\author{
Jing $\mathrm{Xu}$
}

Basic Medicine Department of Medical College, Xian International University, Shanxi, 710077

49164315@qq.com

Keywords: Multidimensional interaction; Pathology; Nursing specialty; Teaching

\begin{abstract}
Objective: The purpose of this study is to explore the practice effect of multidimensional interactive teaching model in pathology teaching of nursing specialty. Method: Two classes of nursing undergraduate of 2015 in our college are selected as the research objects. They are divided into experimental group (45 persons) and control group (45 persons). The control group adopts traditional teaching mode, and the experimental group adopts multidimensional interactive teaching mode. The final exam results of the two classes are compared and made the comparative analysis. Results: The total average score of the experimental group was significantly higher than the control group. The difference between the two groups was statistically significant $(p<0.05)$. Most of the students are satisfied with the multidimensional interactive teaching model and agree that the teaching model should be used in the pathology course. Conclusion: In the teaching of nursing specialty, multidimensional interaction model can stimulate students' interest and initiative, so as to improve the teaching effect.
\end{abstract}

\section{Introduction}

Pathology is an important bridge discipline in basic medicine. By studying the pathological morphologic change of disease, it understands the rule of occurrence and development of disease, so as to provide scientific basis for the diagnosis and prevention of disease. In recent years, with the constant reform of higher nursing education in our country, it is necessary for us to innovate the teaching methods of curriculum. But at present, the pathology is mainly based on the traditional teaching mode, and it takes teacher's teaching as the main body. The students seldom participate in it, passively accept the knowledge of pathology and lack the interest and enthusiasm of learning. In order to cope with the exam, many students learn by rote. They do not have the clinical pathological thinking, and they can not flexibly apply their knowledge to the clinical nursing work. In order to meet the training objectives of the nursing personnel of the twenty-first century and improve the comprehensive quality of nursing staff, we have made a bold attempt in pathology teaching. We used the mobile Internet to facilitate the study, strengthened the communication between teachers and students in a multidimensional interactive mode, and realized a diversified teaching model. This paper summarizes and discusses the application of multidimensional interaction mode in pathology teaching of nursing specialty.

\section{The Basic Viewpoints of Multidimensional Interactive Teaching Mode}

The multidimensional interactive teaching mode refers to a new teaching structure form in the mobile Internet era. It optimizes various factors related to teaching by optimizing teaching interaction, fully arouses the initiative and enthusiasm of students, and forms a multidimensional, multi-level, multi-mode harmonious interaction in order to create the teaching resonance and improve teaching effect[1]. Multidimensional interactive teaching takes students as the main body, and changes the situation that teachers monopolize the classroom and students passively accept the teaching information. It respects students, guides students, and facilitates the multiple interaction between teachers and students, between students and between teachers. Also it takes interactive and enlightening teaching as the main line. The guidance of study, help of study, promotion of study and self-study support each other, and curricular and extra-curricular activities depend on each other. It 
also adopts the teaching methods of scene teaching, micro class and online discussion to cultivate the innovation spirit and practical ability of students.

\section{Materials and Methods}

General Information. Two classes of nursing undergraduate of 2015 in our college are selected as the research objects. They are divided into experimental group (45 persons) and control group (45 persons). There is no statistical significance between the two classes in the aspect of gender, age, entrance scores and basic course score of the first year $(p>0.05)$.

Teaching Method. The control group uses the traditional "input type" teaching mode. Teachers teach students the relevant knowledge according to the syllabus, and the whole teaching process is taught by teachers. The experimental group uses the multidimensional interactive teaching mode. At the end of the semester, a questionnaire survey of teaching mode is conducted on 45 students in the experimental group, and the final examination results of the students in the experimental group and the control group are statistically analyzed.

Statistical Method. SPSS19.0 statistical software is used to make the analysis. The measurement data is expressed as " $\mathrm{n} / \%, \quad \overline{x \pm} s$ ". $t$ test is carried out. Enumeration data is represented by "rate". $\chi^{2}$ test is used, and the inspection level $\alpha=0.05$. When $p<0.05$, the difference was statistically significant.

\section{Results}

The Evaluation of Students in the Experimental Group. At the end of the semester, 45 students in the experimental group were surveyed. 45 questionnaires were issued, and all the questionnaires were collected, so the recovery rate was $100 \%$. Among them, there are 45 valid questionnaires, so the effective rate was $100 \%$. The findings show that, compared with the traditional teaching model, more than $80 \%$ students are satisfied with the effect of the multidimensional interactive teaching model, and they agree to adopt multidimensional interactive teaching model in the teaching of pathology. This kind of teaching mode stimulates the learning enthusiasm and initiative, improves the ability of linking theory and clinic and the communication ability, facilitates the interaction between teachers and students, makes the grasp of knowledge more firmly and improves the learning efficiency. The results are shown in table 1 and table 2 . 
Table 1 Questionnaire survey results of experimental group teaching mode evaluation(\%)

\begin{tabular}{|c|c|c|}
\hline Research Content & $\begin{array}{c}\text { Traditional } \\
\text { teaching mode }\end{array}$ & $\begin{array}{l}\text { Multidimensional } \\
\text { interactive teaching } \\
\text { model }\end{array}$ \\
\hline $\begin{array}{l}\text { Which teaching mode are you more } \\
\text { interested in? }\end{array}$ & $6(13.3)$ & $39(86.7)$ \\
\hline $\begin{array}{l}\text { What kind of teaching mode do you } \\
\text { think can improve learning } \\
\text { enthusiasm and initiative? }\end{array}$ & $6(13.3)$ & $39(86.7)$ \\
\hline $\begin{array}{l}\text { Which teaching mode do you think } \\
\text { can enhance the memory of } \\
\text { knowledge? }\end{array}$ & $5(11.1)$ & $40(88.9)$ \\
\hline $\begin{array}{l}\text { Which teaching mode do you think } \\
\text { can increase student participation? }\end{array}$ & $3(6.7)$ & $42(93.3)$ \\
\hline $\begin{array}{l}\text { What kind of teaching mode do you } \\
\text { think can help students to } \\
\text { communicate with each other? }\end{array}$ & $3(6.7)$ & $42(93.3)$ \\
\hline $\begin{array}{l}\text { What kind of teaching mode do you } \\
\text { think can promote communication } \\
\text { between teachers and students? }\end{array}$ & $2(4.4)$ & $43(95.6)$ \\
\hline $\begin{array}{l}\text { What kind of teaching mode do you } \\
\text { think will facilitate the } \\
\text { understanding of content? }\end{array}$ & $5(11.1)$ & $40(88.9)$ \\
\hline $\begin{array}{l}\text { What kind of teaching mode do you } \\
\text { think can improve the ability of } \\
\text { using knowledge? }\end{array}$ & $4(8.7)$ & $40(91.1)$ \\
\hline $\begin{array}{l}\text { What kind of teaching model do you } \\
\text { think should be adopted in the } \\
\text { teaching of pathology? }\end{array}$ & $6(13.3)$ & $39(86.7)$ \\
\hline
\end{tabular}

Table 2 The satisfaction of the experimental group to the multidimensional interactive teaching $\operatorname{model}(\%)$

\begin{tabular}{cccc}
\hline Survey content & Yes & No & Uncertainty \\
\hline $\begin{array}{c}\text { Are you satisfied with } \\
\text { the multidimensional } \\
\text { interactive teaching } \\
\text { model? }\end{array}$ & $38(84.4)$ & $2(4.4)$ & $5(11.1)$ \\
$\begin{array}{c}\text { Is it better than the } \\
\text { traditional teaching } \\
\text { mode? }\end{array}$ & $36(80.0)$ & $1(2.2)$ & $8(17.8)$ \\
\hline
\end{tabular}

Comparison of the Theoretical Examination Results between Two Classes. The total average score of the theoretical test in the experimental group is significantly higher than that in the control group, and the difference between the two groups is statistically significant $(p<0.05)$. In addition, the number of the people whose scores are more than 80 in the experimental group is significantly more than the control group, as shown in table 3. 
Table 3 The theoretical examination results of two classes $(\mathrm{n} / \%, \quad \overline{x \pm s})$

\begin{tabular}{llllllll}
\hline Group & $\begin{array}{c}\text { Number } \\
\text { of cases }\end{array}$ & $<60$ & $61 \sim 70$ & $71 \sim 80$ & $81 \sim 90$ & $\begin{array}{l}91 \sim- \\
100\end{array}$ & $\begin{array}{c}\text { Total } \\
\text { average } \\
\text { score }\end{array}$ \\
\hline $\begin{array}{c}\text { Experime } \\
\text { ntal group } \\
\begin{array}{c}\text { Control } \\
\text { group }\end{array}\end{array}$ & 45 & $2(4.4)$ & $3(6.7)$ & $8(17.8)$ & $19(42.2)$ & $13(28.9)$ & $82.6 \pm 11.7$ \\
\hline
\end{tabular}

\section{Discussion}

In recent years, with the continuous improvement of the nursing personnel training program, the pathology teaching must combine the clinical nursing work and the requirements of CLEN, and take the "necessity and sufficiency" as the principle. The pathology teaching content is more abstract, and there are many concepts and morphology descriptions of pathological changes, and also it is difficult to remember the theoretical knowledge and master the microsopic structure, so the pathological changes of different lesions are easily confused[2]. But the traditional teaching method can not achieve the "student centered" form, and it is also a passive teaching based on the mode that "teachers speak and students listen". The participation rate of students in class is very low, the interaction with teachers is too little, and the teaching effect is not satisfactory[3]. The essence of the unity of teaching and learning is "interaction and communication". Without communication and interaction, it is not the real teaching. Therefore, it is necessary to use the multi-dimensional interactive teaching mode to design the pathology teaching.

Reorientation of Curriculum Learning Goal . In the traditional teaching mode, the curriculum learning goal is to let the students master, familiar with or understand the knowledge points. This concept has no specific measurement indicators, and can not evaluate the teaching effect. For the nursing profession, the main purpose of learning pathology is to enable students to understand the pathological changes, and lay the foundation for the study of clinical courses, so as to guide the diagnosis and operation of nursing. Therefore, the learning goal should be changed as: The first point is to enable students to identify the shapes of common pathological specimens (including general samples and pathological sections) with the naked eye and microscope. The second one is that students can correctly analyze the common cases. The third one is that students can learn to use pathology knowledge to guide nursing operations and lay a foundation for clinical nursing courses. The fourth one is that in combination with the requirements of CLEN, part simulated examination exercises of pathology should be strengthened. This kind of target positioning can be evaluated by case analysis and discussion, and experimental and final examination paper evaluation, so as to test students' learning results.

The Optimization of Teaching Content and the Reflection of Characteristics of Nursing Speciality. We should focus on the training target of nursing professional ability, and select the teaching content related to clinical nursing work as the key point. The general content of pathology is the ladder for students to go to clinical courses and the bridge to enter the clinic, so it must be explained clearly and deeply[4]. However, students will continue to study the content of each theory in the clinical curriculum, so it can be appropriately reduced. For example, the pathological changes and outcomes of congestion and extravasated blood can guide the pumping and trauma bandaging, hrombosis and embolic lesions can guide the nursing work to prevent the formation of thrombus, air, fat and other emboli in blood, and the basic pathological changes and clinical manifestations of inflammation can guide how to protect, and correctly carry out nursing work. From the practical point of view, in the nursing work, we mainly judge the state of an illness according to the patient's vital signs and gross morphologic lesion, so it is necessary to downplay the microscopic structure and strengthen the study of the gross samples. After the optimization of pathology teaching content combining with the nursing specialty characteristics, the key teaching points is prominent and practical, which is more conducive to the development of multidimensional interactive teaching 
mode.

The Application of Various Teaching Modes. The first one is in the classroom teaching level. Multiple teaching modes should be used: the first one is the PPT demonstration teaching method. The process of the formation of the abstract pathological changes should be displayed in animation and video form to attract the students' attention and help to improve their interest in learning. The second one is the situational teaching method. The role play teaching method[5] should be used to enhance the interaction between teachers and students. In classroom teaching, teachers can design a scene according to the content of the course. For example, if the teachers want to teach the air embolism, they can let students participate in the role of the patient and nurse, and let the nurse carry out intravenous fluids for the patient. Through the discussion of the operation process, the students will be able to understand how air embolism occurs and how to prevent it. Teachers can also ask questions, and let students answer, in order to create a divergent thinking classroom atmosphere. The third one is the clinical case discussion. In the pathology experiment class, the teachers are asked to organize the students for case analysis and discussion by combining the observation of pathological specimen in order to train students' ability to understand problems, analyze problems and solve problems, and cultivate the team work ability[6].

The second one is in extracurricular teaching level. WeChat supports the transmission of video, pictures, text and voice, and has the characteristics of sociability, mobility and multimedia[7], so it is popular among college students. We set up WeChat group in class, and the teacher will publish the teaching PPT, video and case questions of each class in WeChat group, so that students can review after class, preview in advance and find case analysis data in time. Through the WeCaht group, a two-way communication channel between students and teachers can be established. The teacher can answer questions raised by students in the WeChat group, and students can discuss the case analysis in groups, so as to enhance the interaction between students. In this way, not only the shortcomings of insufficient classroom time are solved, but also the advantages of sharing teaching resources are brought into play. In addition, students are also asked to download "Added Value of Health Care Books" APP on their mobile phones, and watch the teaching courseware and answer the questions at any time on the mobile phone.

After using the above teaching methods, the experimental group compares with the control group. We can find that the learning attitude and exam results of students improve significantly, and the classroom participation and learning initiative also improve[8]. It plays an important role in cultivating students' autonomous learning ability.

The use of multidimensional interactive teaching mode can achieve the interaction between pathology and other basic subjects. There are many repetitive contents in textbooks such as Physiology, Biochemistry, Pathology, so this will not only waste classroom teaching time, but also make students weary of study[9]. Basic medicine teaching and research section can carry out the collective lesson preparation and other teaching and research activities. In that way, teachers can exchange the teaching idea and integrate the teaching content, and also the interaction between teachers can be increased, which can be conducive to creating the efficient and harmonious teaching team.

\section{Conclusion}

The application effect of multidimensional interactive teaching mode in pathology teaching is very good. It realizes the interaction between teachers and students, between teachers and between students in a single subject, breaks the pattern that basic courses fight by themselves, and forms on overall linkage situation[10]. The application of various teaching methods is beneficial to stimulate students' interest in learning and arouse their enthusiasm in study. It is of great significance to train the post professional competence and improve the effect of pathology teaching.

\section{References}

[1] Y.Q.Sun, J.B.Yin, S.Y.Gan, etc: A Discussion of Multi-Dimensional Interactive Methods of 
Teaching Basic Medical Education[J], Journal of Pathogen Biology, 2015, 10(2):4-5.(In Chinese)

[2] H.Liu, X.H.Wang, W.H.Cai, etc: The Reform of Pathology Teaching Method - Theory and Experiment Synchronization[J], Heilongjiang Medical Journal, 2013, 37(5):397-399.(In Chinese)

[3] C.J.Chen: Establishment and Implementation of Multidimensional Interactive Teaching Model in Large Class Environment - From the Perspective of Ideological and Political Theory Course[J], Heilongjiang Researches on Higher Education, 2008(11):147-150.(In Chinese)

[4] X.Y.Xu, X.S.Li, L.X.Zhang. Etc: Reform of the Pathology Curriculum Design Based on Training Objective of Higher Vocational Nursing Speciality[J], Journal Modern Medical and Health, 2014, 30(2):295-296.(In Chinese)

[5] L.Qin: Role Playing Method: Exploration of Simulation Teaching Model of Vocational Education[J], Time Education, 2010(7):264.(In Chinese)

[6] D.X.Zhou, Y.Sun, L.P.Mo, etc: Application of PBL Teaching Model in Pathological CPC Experimental Teaching [J], Basic Medical Education, 2016, 18(12):988-990.(In Chinese)

[7] D.Y.Liu: Application Experience of WeChat Public Platform in Pathology Teaching Interaction [J], Intelligence Education, 2016, 172(8):200.(In Chinese)

[8] Y.X.Wang: The Research on Application of the Pathology Theory and Experiment Integration Teaching Model[J], China Medical Equipment, 2017, 13(7): 117-120.(In Chinese)

[9] C.Tang, J.Yi, H.Huang, etc: Research on Multi Dimensional Interactive Teaching Model Guided by Tasks[J], Science and Technology Innovation Herald, 2013(27): 224.(In Chinese)

[10] L.Zhang, Y.T.Xu, Q.L.Wang, etc: Application of Case Teaching in Pathological Teaching Reform[J], Basic Medical Education, 2015, 17(4): 281-283.(In Chinese) 